Derleme Makale

\title{
Etlik Piliç Üretiminde Civciv Kalitesini Etkileyen Faktörler ve Kalite Sınıflandırılmasında Kullanılan Kalitatif Parametreler
}

\author{
Murat DURMUŞ*
}

Hasan RÜŞTÜ KUTLU

\begin{abstract}
Özet
Kanatlı eti üretiminde ekonomik yapıyı, miktarı ve kaliteyi etkileyen birçok faktör (genetik faktörler, sürü yaşı, kuluçkalık yumurta kalitesi, yumurta toplama zamanı, yumurta depolama, kuluçka sıcaklığı, civciv kalitesi vs.) vardır. Bu faktörler damızlık hayvanların beslenmesinden, piliçlerin kesimine kadar uzun bir süreci kapsar. Bütün bu faktörlerin etkilerine bağlı olarak farklı kalitelerde civciv üretimi gerçekleşmektedir. $\mathrm{Bu}$ faktörler arasında civciv kalitesi diğer tüm parametrelerin birleşiminden oluştuğundan yüksek verim için en önemli kriterdir. Bu derlemede; civciv kalitesinin önemi, civciv kalitesini etkileyen faktörler ve civciv kalite sinıflandırılmasında kullanılan kalitatif parametreler incelenmiştir.
\end{abstract}

Anahtar Kelimeler: Kuluçka, Yumurta Kalitesi, Damızlık Sürü, Kalitatif Parametreler.

\section{Factors Affecting Chick Quality in Meat Chicken Production and Qualitative Parameters Used in Quality Classification}

\begin{abstract}
There are many factors (genetic factors, flock age, hatching egg quality, egg collection time, egg storage, incubation temperature, chick quality, etc.) which affect the economical, quantity and quality in poultry meat production. These factors include a long period from feeding of breeding animals to cutting of chickens. Depending on the effects of all these factors, different quality chicks are produced. Among these factors, chick quality is the most important criterion for high yield as it consists of a combination of all other parameters. In this review, importance of chick quality, factors affecting chick quality and qualitative parameters used in chick quality classification are examined..
\end{abstract}

Key Words: Incubation, Egg Quality, Breeding Herd, Qualitative Parameter

ORCID ID (Yazar sirasına göre)

0000-0002-4221-7449, 0000-0002-3891-1534

Yayın Kuruluna Geliş Tarihi: 23.08.2019

Kabul Tarihi: 05.11.2019

*Çukurova Üniversitesi, Ziraat Fakültesi, Zootekni Bölümü, Adana

E-mail: durmusm@cu.edu.tr 


\section{Etlik Piliç Üretiminde Civciv Kalitesini Etkileyen Faktörler ve Kalite Sınıflandırılmasında Kullanılan Kalitatif Parametreler}

\section{Giriş}

Nüfusun artmasıyla birlikte her geçen gün hayvansal gıdaya artan talebin karşılanması ve insanların dengeli bir şekilde beslenmesini sağlamak için kanatlı eti üretiminin arttırılması ve kalitesinin yükseltilmesi kaçınılmaz hale gelmiştir. $\mathrm{Bu}$ nedenle üretime iyi kaliteli civcivlerle başlamak tavukçuluk endüstrisinde ister yumurta tavukçuluğu ister etlik piliç yetiştiriciliğgi olsun karlılığın ön koşullarından birisidir. Bu bağlamda günlük civcivlerin kalitesi üretime iyi bir başlangıç ve kesim performansı için çok önemlidir (Meijerhof, 2009). Kalitesi düşük civcivlerle üretime başlanılması durumunda ileride telafi edilemeyen verim kayıpları ortaya çıkabilir. $\mathrm{Bu}$ nedenle yumurtadan çıkan civcivin yüksek kaliteli olması damızlık ve kuluçkahane birimlerinin ortak noktasıdır. Burada önemli olan tüketici isteğine uygun kalitede piliç eti üretimi gerçekleştirmek için kaliteye etki eden faktörleri bilerek ve bu faktörleri dikkate alarak üretim yapmaktır. Bu kapsamda; piliç eti kalitesi üzerinde etkili olan faktörler araştırılmış ve araştırılmaya devam edilmektedir. Kaliteli civciv, kuluçka süresince optimal gelişme gösteren, kuluçka çıkışı büyüme oranı, göğüs eti oranı ve yaşama gücü yüksek olan civciv olarak tanımlanabilir. Fakat bu tanıma dayanarak üretimin başlangıç aşamasında hedeflenen performans parametrelerine ulaşmak için gerekli olan civciv kalitesini kalitatif olarak ortaya koymak oldukça zor ve subjektif bir konudur. $\mathrm{Bu}$ nedenle ülkemizde özellikle üretimin başlangıç aşaması olan kuluçka çıkışı sonrası, civcivler üzerinde uygulanan herhangi bir kalite siniflandirmasi olmadığından hangi civcivden yüksek performans alınacağı bilinmemektedir. Oysa civcivler üzerinde belirlenen kalite parametrelerinin kuluçka çıkışı sonrası tespit edilip üretime civcivler üzerinde belli bir kalite sınıflandırması yaparak başlamak, istenen performansı elde etmede daha etkili olacaktır. Ülkemiz kanatlı sektöründe kuluçkadan çıkan civcivler doğrudan üretim kümeslerine alınmaktadır. Ortalama 35-42 günde kesim ağırlığına ulaşan civcivlerin üretime alınmasından kesime kadar; gerek et kalitesini gerekse üretim ekonomisini etkileyen civciv ölümleri, gelişme geriliği ve hastalıklar gözlenmektedir. Üretime alınan civcivin kesime kadarki süreçte sağlıklı ve istenilen miktar ve kalitede verim vermesi için üretime doğru civcivle başlamak verimi arttırıp her türlü kayıpları minumuma indirme açısından çok önemlidir. Bilindiği gibi civcivlerin $35-42$ günlük besi sürecinin ilk haftası; sindirim, bağışıklık ve iskelet sisteminin gelişimi gibi civcivin sonraki dönemlerini de etkileyecek bir çok hayati durum açısından oldukça önemlidir. $\mathrm{Bu}$ nedenle civcivlerin ilk haftalık süreçte iyi bir başlangıç yapmaları civcivlerin kalitesiyle doğrudan ilgilidir.

\section{Civciv Kalitesine Etki Eden Faktörler}

Civciv kaltesine etki eden faktörler damızlık hayvanların beslenmesinden piliçlerin kesimine kadar ki süreçte etkisini gösterir. Civciv kalitesini etkileyen faktörler kuluçka öncesi (damızlık yumurta kalitesi, damızlık yumurtaların toplama-depolama koşulları ve süresi, damızlık sürünün genotipi ve yaşı, damızlıkların bakım-yönetimi vs.), kuluçka esnası (kuluçka makinesinin iç koşulları = sicaklık, nem, yumurtaların çevrilmesi ve havalandırma) ve kuluçka sonrası (çıkışı takiben ilk 7 gün) olmak üzere 3 döneme ayrilır (Şekil 1.).

\section{Kuluçka Öncesi}

Kuluçka öncesi dönemde civciv kalitesine etki eden faktörler, öncelikli olarak kuluçkalık yumurtaların elde edildiği damızlık hayvanların genetik yapısına, yaşına, bakım ve beslenmelerine bağlıdır. Sonrasında ise yumurtaların kuluçka makinesine koyulmasına kadar geçen sürede yumurtaların toplanması, taşınması, kuluçkaya uygunluğuna göre tasnif edilmesi ve kuluçka öncesi depolanma hassasiyetine bağlidır.

Genetik faktörler; Damılık yumurtanın albümin miktarı, kabuk kalınlığı, kabuk kırılma direnci, şekil indeksi, kabuk rengi ve yumurta büyüklüğü gibi genetikten kaynaklanan özellikleri kuluçkadan çıkan civciv sayıs1 ve kalitesini etkilemektedir 


\section{Etlik Piliç Üretiminde Civciv Kalitesini Etkileyen Faktörler ve Kalite Sınıflandırılmasında Kullanılan Kalitatif Parametreler}

(Şekil 2.). $\mathrm{Bu}$ nedenle yumurta kalite özellikleri iyi olan damılıkların civciv kalitesi de iyi olmaktadır (Decuypere ve ark., 2001; Tona ve ark., 2007).

Damızlık yaşı; Kuluçkalık yumurtaların elde edildiği damızlık sürü yaşının kuluçka randımanı ve yumurtadan çıkan civcivin
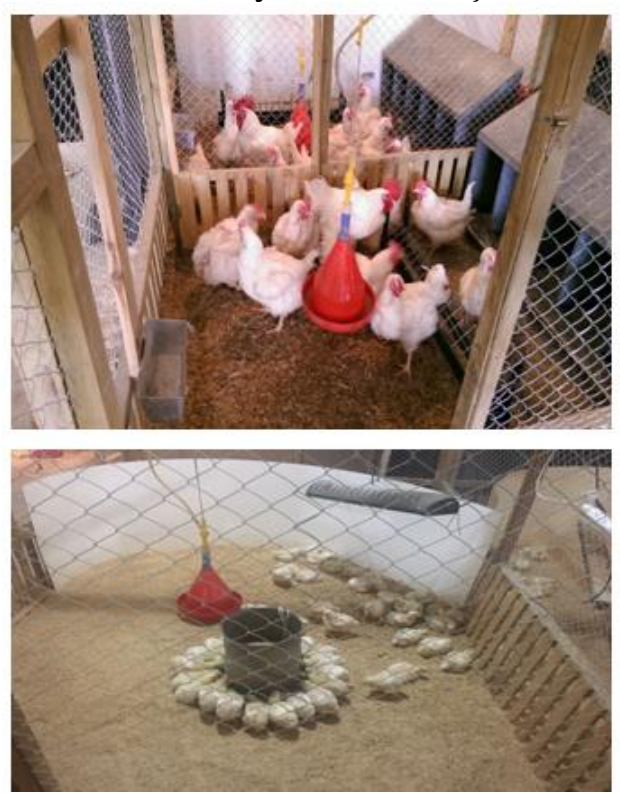

Şekil 1. Kaliteli civciv üretim aşamaları

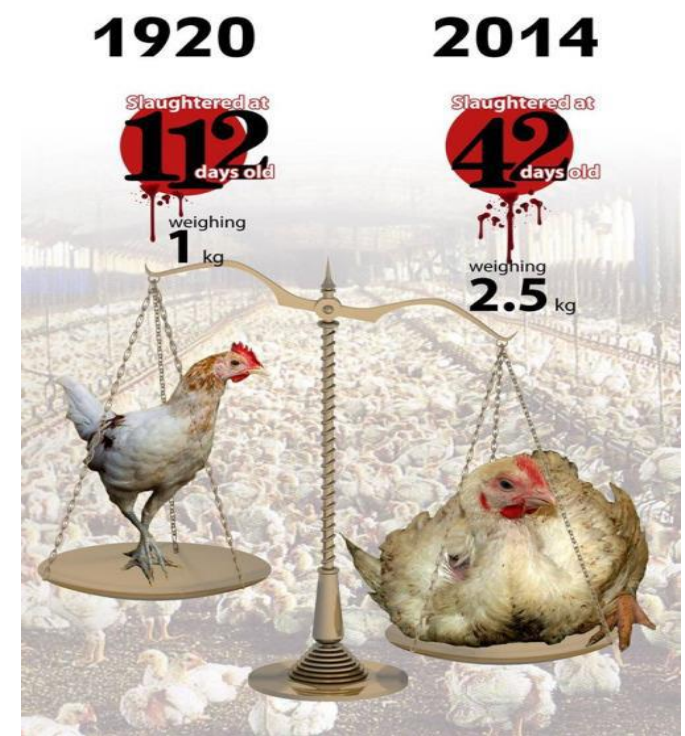

Şekil 2. Genetiğin etkisi

Damızlıkların yaşı arttıkça yumurta boyutu artacağından, büyüme performansı açısından kuluçka randımanı ve civciv kalitesinin iyileşmesine yol açabilir. Yumurtanın büyüklüğü, doğrudan günlük civciv ağırlığını kalitesi üzerine etkisi büyüktür. Damızlık hayvanlardan elde edilen yumurta ağırlığına göre günlük civciv ağırlığının değişeceği ve bununda damızlık hayvanların yaşı ile ilgili olduğu bilinmektedir (Mather ve Laughlin, 1979; Okur 2008; Şeremet, 2012; Anonim, 2019a).
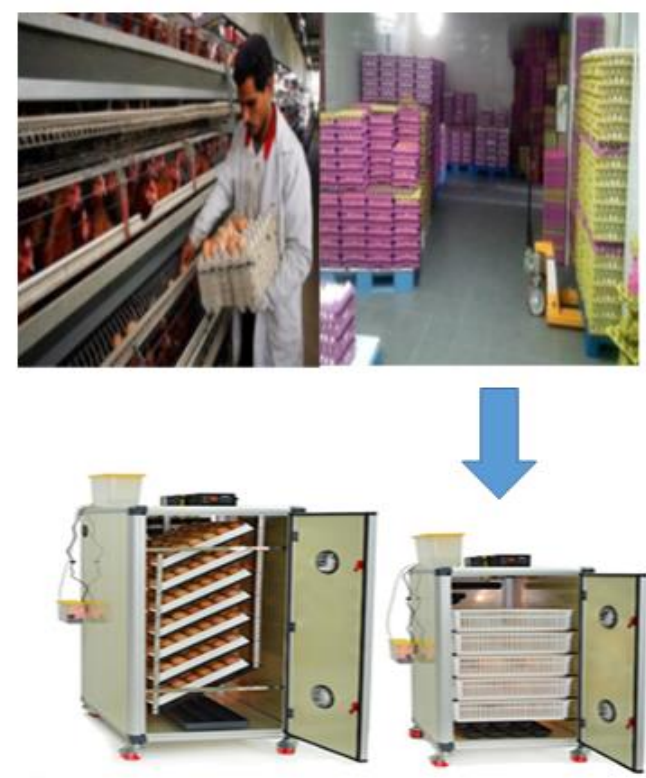

etkileyeceğinden dolayı önemlidir (Moran, 1990). Buna bağlı olarak Hill (2001) yaptığ1 çalışmada, damızlık yaşının artmasıyla elde edilen günlük civciv boyunun arttığını bildirmiştir. Fakat farklı damızlık yaşlarının karşılaştırıldığı çalışmalarda, yaşlı damızlıklarda özellikle depolama ile birlikte yumurta akı yükssekliğinin azaldığı, embriyo ölümleri ve 1skarta civciv oranının arttığı görülmüştür (Lapao ve ark., 1999). Tona ve ark. (2003) yaptıkları çalışmada yaşlı sürülerde depolamaya bağlı olarak Haugh Birimi ve civciv kalitesinin azaldığını belirlemişlerdir. Genç damızlıklarda ise yumurta ağırlıkları düşmesine rağmen elde edilen yumurtaların daha iyi albumen kalitesine ve daha yüksek çıkım gücüne sahip olduğu dolayısıyla daha fazla sayıda kaliteli civciv elde edildiğini bildirmiştir (Tona ve ark., 2004).

Yumurta kalitesi; Yumurta kalitesi, kuluçka sonuçlarını etkileyen önemli bir faktördür (Elibol, 2009). Elde edilen kuluçkalık 


\section{Etlik Piliç Üretiminde Civciv Kalitesini Etkileyen Faktörler ve Kalite Sınıflandırılmasında Kullanılan Kalitatif Parametreler}

yumurtalar üzerine damılık hayvanların bakım ve beslenmesi, yaşı, genetiği ve çevre gibi faktörler etkilidir (Atasoy ve ark., 2001). Damızlık tavuklardan elde edilen yumurtaların çok büyük veya küçük oluşu kuluçka randımanını düşürmekte ve bu tür yumurtalarda çıkış gücü ve civciv kalitesi düşük olmaktadır (Şekil 3.). Hava boşluğu uygun yerde oluşmamış yumurtaların çıkış güçleri, hava boşluğu normal oluşan yumurtalara göre daha düşük olmaktadır (Kamanlı ve Durmuş, 2014).

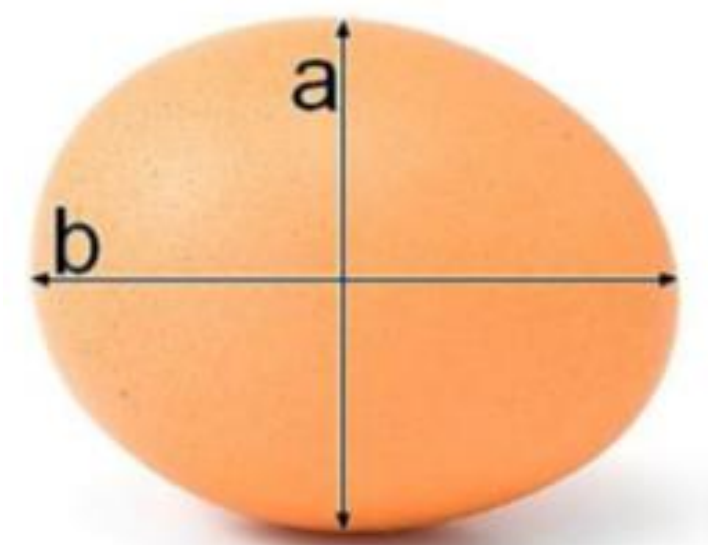

Șekil indeksi $=100 \mathrm{X}(\mathrm{A} / \mathrm{B})$

\section{Şekil 3. Yumurta şekil indeksi}

İnce kabuklu, gizli çatlaklı, dışkı ile bulaşık vb. yumurtaların kuluçka sonuçlarını olumsuz etkilemesi nedeniyle kuluçkalık olarak değerlendirilmesi kuluçka randımanı ve civciv kalitesini düşürmektedir (Şekil 4.). Anormal şekilli yumurtalarda çıkış gücünün düşük olduğu ancak civciv kalitesinin bu özellikten etkilenmediği çeşitli araştırmalarla tespit edilmiştir (Kamanlı ve ark., 2010).
Yumurta toplama; Damızlık sürülerden elde edilen yumurtalar kuluçka amaçlı üretildiği için yumurtaların birikmesi ile oluşabilecek kirlenme, kırık-çatlak gibi durumlardan kaçınmak için damızlık sürülerde günlük olarak 2-3 defa yumurta toplanması gerekir. Aksi halde yumurtaların birbirine çarpmasıyla görünmez çatlaklar ya da yumurtaların dışkı ile kirlenmesi kuluçka randımanını ve civciv kalitesini düşürmektedir. Toplanan yumurtaların viyollere rastgele değil aynı büyüklükteki yumurtaların aynı viyol içerisine konmasına dikkat edilmeli ve depolanacağı yere taşınmasında da dikkatli olunmalıdır.

Yumurtaların depolanması; Kuluçkalık yumurtalar, kuluçka randımanı üzerinde az veya hiç etkisi olmadan 7 güne kadar saklanabilir. Ancak 1 haftadan fazla saklandığında, embriyonik anormallikler ve mortalite artmaktadır. Yumurtaların 7 günün üzerinde depolanması kuluçka süresinde uzamaya ve bununla birlikte kuluçka randımanında ve civciv kalitesinde düşmeye sebep olmaktadır. Kuluçkalık yumurtaların 7 günün üzerinde depolanan her gün için civcivin yumurtadan çıkış süresini 1 saat uzattığı yapılan çalışmalar ile belirlenmiş̧ir (Mirosh ve Becker, 1974). Yumurtanın depolanması ile yumurta ak1, dolayısı ile Haugh Birimi ve civciv kalitesi olumsuz yönde etkilenmektedir (Tona ve ark., 2003). Kuluçka öncesi yumurtaların tutulduğu sicaklık ve nem değerleri gelişme eşiğinin altında olmalıdır. Kuluçkalık yumurtalar depolama odasında genellikle 3-4 gün kalırlar. Bu süre boyunca depolamada 18$20^{\circ} \mathrm{C}$ sicaklık ve \% 75-80 nispi nem uygundur. 


\section{Etlik Piliç Üretiminde Civciv Kalitesini Etkileyen Faktörler ve Kalite Sınıflandırılmasında Kullanılan Kalitatif Parametreler}

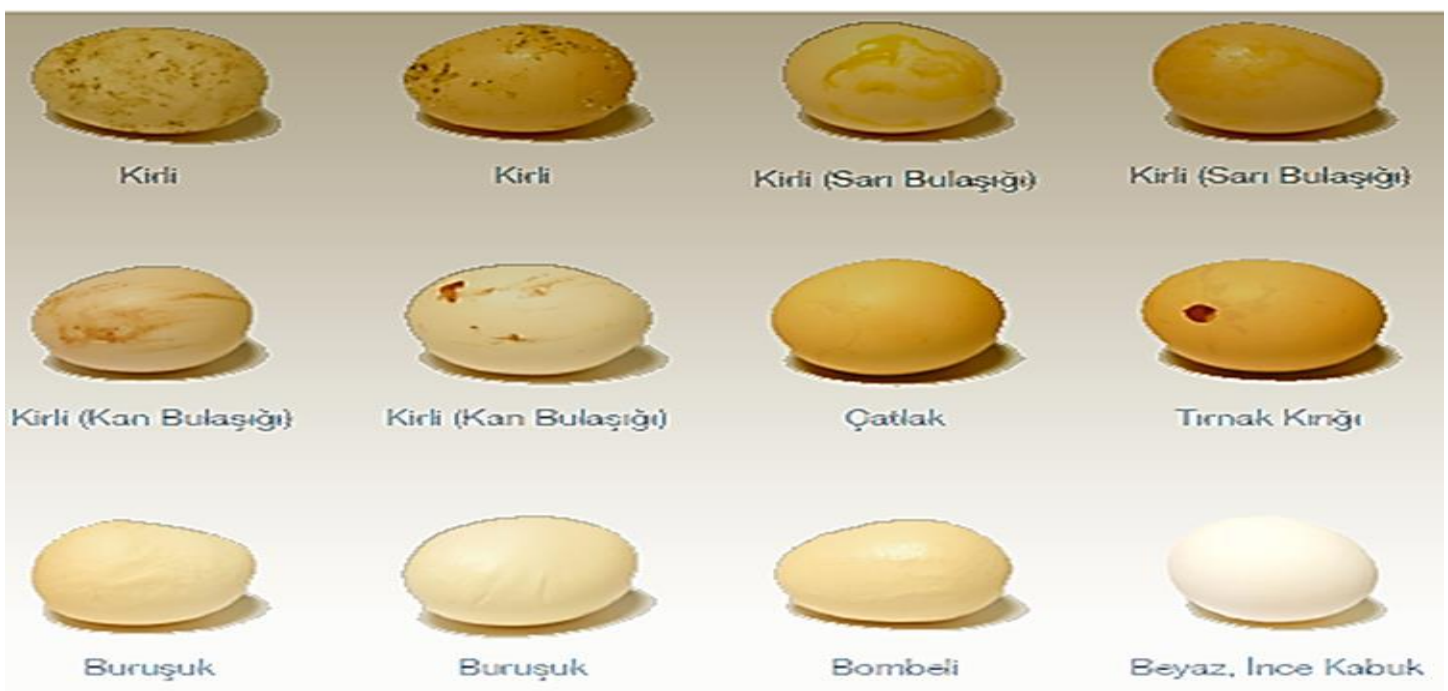

Şekil 4. Anormal şekilli yumurtalar

Damızlıkların beslenmesi; Yumurta içinde embriyonel gelişimin sorunsuz bir şekilde gerçekleşmesi, yumurtadan çıkan civcivin yüksek kaliteye ve güçlü bir bağışıklık sistemine sahip olması kuluçka makinesine konan yumurtanın besin madde içeriğine bağlıdır. Yumurta içindeki besin maddeleri ise damılık hayvanların beslenmesi ile doğrudan ilişkilidir. Damızlık hayvanların beslenmesi besin madde gereksinmesi değişen büyütme ve verim dönemi olarak ikiye ayrılır. $\mathrm{Bu}$ hayvanların yemlenmesi, uygun yaş ve ağırlıkta eşeysel olgunluğa ulaşması ve maksimum verimin alınabilmesi için her iki dönemde de nitel ya da nicel olarak yem kısıtlaması yapılmalıdır. Aksi halde tavukların verdiği yumurta sayısı azalmakta, horozların damızlıkta kullanım etkinliği ve süresi düşmektedir (Kutlu, 2018). Büyütme dönemlerinde (0-20 hafta yaşlar arası) dişi ve erkek damılıkların besin madde gereksinimleri ve yem istekleri herhangi bir verim söz konusu olmadığ 1 için birbirine benzerdir. $\mathrm{Bu}$ nedenle büyütme döneminde erkek ve dişi damızlıklar aynı yemi tüketebilirler. Fakat damızlıkların eşeysel olgunluğa erişmesi ile cinsiyete göre rasyonlarında birtakım değişiklikler yapılmalıdır. Dişi damızlıklar büyütme döneminde $\% 1 \mathrm{Ca}$ içeriğine sahip rasyonlar ile beslenirken verim dönemine geçilmeden 1-2 hafta önce rasyonun $\mathrm{Ca}$ düzeyi $\% 3.5$ seviyelerine çıkarılmalıdır (Kutlu, 2018). Yüksek eşeysel aktivite, sperma miktarı ve kalitesi, aşım gücü ve yumurtaları dölleme düzeyinin yüksekliği horoz için en önde gelen verim kriterleridir. Özellikle yemlerdeki aminoasitler vitamin $\mathrm{A}, \mathrm{E}$ ve $\mathrm{C}$ ayrica selenyum gibi iz elementlerin dengesizliği sperma üretimini olumsuz yönde etkiler (Kutlu, 2018). Horozlar yumurta vermedikleri için besin madde gereksinmeleri yüksek değildir. Yaşama, büyüme ve sperm verimi için besin maddesine gereksinim duyarlar. Horozların 20-22. haftadan itibaren dişi damızlıkların bulunduğu kümeslere katılması ile horozlara verilecek yem, dişi damızlıklara verilecek yemden farklı olmalidır.

\section{Kuluçka dönemi}

Kuluçka makinesine konulmasıyla yumurta içinde bulunan besin maddeleri ve makinenin sağladığı yapay koşullara bağlı olarak 21 günün sonunda civcivlerin bazıları yumurtadan canlı olarak çıkarken bazıları da çıkış evresinde ölmektedir. Kuluçka esnasında yumurtanın şekil ve boyutuna ve besin madde içeriğine etki edilemez. $\mathrm{Bu}$ dönemde optimal bir çıkış randımanı için 21 günlük kuluçka süreci boyunca civcivin gelişimini destekleyecek şekilde uygun çevre koşullarının sağlanması gereklidir.

\section{Kuluçkayı etkileyen faktörler;}

Sıcaklık; Döllü bir yumurtanın canlı bir varlık haline dönüşümünde en etkili faktör sicakl1ktır. Makinenin 1sitılma sistemi ne 


\section{Etlik Piliç Üretiminde Civciv Kalitesini Etkileyen Faktörler ve Kalite Sınıflandırılmasında Kullanılan Kalitatif Parametreler}

olursa olsun değişmeyen ve uyulması gereken tek esas, ortalama sıcaklı̆̆ın düzenli olarak yumurtadaki embriyoya iletilmesidir. İletilecek ortalama sıcaklık gelişim evresinde $37.7^{\circ} \mathrm{C}$ çıkış evresinde $36.7^{\circ} \mathrm{C}^{\prime}$ dir. Normalin üstündeki yüksek sıcaklık $42^{\circ} \mathrm{C}$, normalin altındaki sıcaklık $35^{\circ} \mathrm{C}$ olarak kabul edilir. $\mathrm{Bu}$ durumlarda uzun süre kalan yumurtalarda embriyo ölümleri gerçekleşmektedir (Elibol, 2018).

Nem; Doğal kuluçkada hayvan tarafindan sağlanan nem, makinelerdeki ortamın çok farklı olması nedeniyle nemin düzenlenmesini gerekli kılmaktadır. Nemin yetersiz olduğu ortamda yumurtada su kaybı normalin çok üstünde olur ve hava boşluğu fazla büyür (Şekil 5.). Bunun sonucunda civciv yumurta içinde sıkışıp yumurtadan çıkamaz. Ayrıca aşırı su kaybına uğramış civciv yumurta içerisinde ölmüş de olabilir. Nemin yüksek olduğu ortamda ise hava boşluğu küçük kalır bunun sonucu olarak ortamda yeterli düzeyde hava olmadığından embriyo boğulabilir (Elibol, 2018).

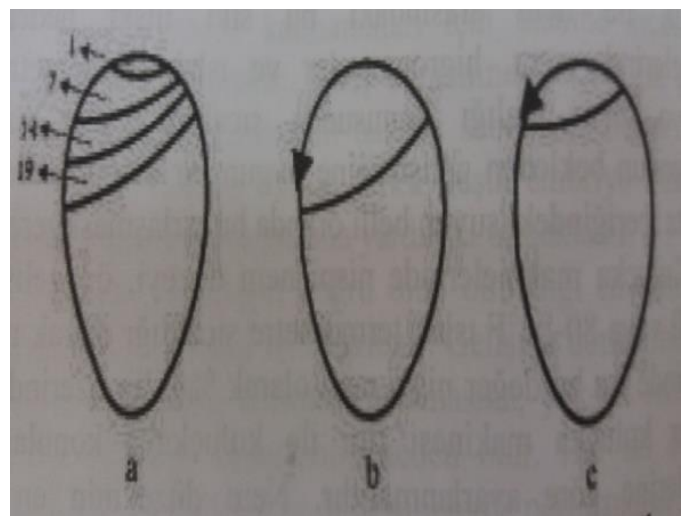

Şekil 5. Yumurta hava boşluğunun durumu

Her iki durumda da embriyo zarar görür ve civciv kalitesi olumsuz etkilenir. Makinelerde sicak hava bir akım yaptığından yumurta yüzeylerine temas ederek geçer. Bunun sonuncunda yumurta bünyesindeki suyu buharlaştırarak emer ve yumurtaların kurumasına neden olur. Sonuç olarak, dokularda azalmış olan su embriyonun ölümüne neden olur. Makinelerde yumurta bünyesindeki suyun buharlaşmasına engel olmak için makine içindeki ısınmış kuru havanın su ile nemini yükseltip homojen halde dağılmasını sağlamak gerekir. $\mathrm{Bu}$ yüzden makine içerisinde bir su kabı konulur böylece ortamın nemini ayarlayarak kuru havaya dönüşmesi önlenmiş olur. Kuluçka makineleri için gelişim bölümünde \% 50-60 bağıl nemin olması istenir. Çıkış evresinde ise bu nem miktarının \%65-70 bağıl nem seviyesine çıkarılmış olması gerekir (Elibol, 2018).

Havalandırma; Bütün canlılar gibi kuluçkaya konulmuş ve yumurta içinde gelişmekte olan embriyonun da temiz havaya ihtiyacı vardır. Yumurta içinde embriyo gelişimi sırasında yumurta kabuğunda bulunan porlar aracılığıyla oksijen alıp ortama karbondioksit salarak gaz alışverişinde bulunur. Ortama salınan karbondioksitin birikip civciv kalitesini olumsuz etkileyecek şekilde zararlı hale gelmemesi için yeterli havalandırma şarttır. Ayrıca havalandırma ile ortama sicaklık ve nemin homojen bir şekilde dağılımı da sağlanmış olur.

Yumurtaların çevrilmesi; Yumurtaların çevrilmesiyle yumurta yüzeyindeki sıcaklık farkının ortadan kaldırılması ve embriyonun ilk gelişme döneminde ruşeym torbasının (germinal disk) daha sonrasinda ise embriyonik zarların kabuk zarlarına veya bu zarların birbirlerine yapışmaları önlenir. Döllü yumurtaların yaklaşık \%25'inde kuluçkaya konulduklarında ruşeym ekseni yanlış durumda bulunmakta olup bu hatalar yumurtaların çevrilmesi ile düzeltilir. Kuluçka süreci boyunca kalp ve kan damarlarının oluşumu, kanat ve bacakların belirmesi ve gelişimi, göz ve beyinin belirip gelişmesi, gaga oluşumu, tüylerin oluşumu ve gaganın açılması gibi evrelerin tamamlanmasina kadar olan zamanda civciv yumurta içinde yumurtanın enine uzanmaktadır. Kuluçkanın 12-13. gününden sonra, iç ve dış organlar bakımından belirgin hale gelen civciv büyümeye başlar ve yumurtanın enine uzunluğuna sığamaz. $\mathrm{Bu}$ evreden sonra civciv kafasını bacaklarının arasına alarak karnına çeker ve yumurtanın içinde kafası hava boşluğuna gelecek şekilde yumurtanın uzunlamasına doğru dönmeye başlar (Şekil 6.). Bu olay yumurtanın 1 saat aralıklar ile 45 derecelik açıla sağa-sola çevrilmesi ile sağlanır. Aksi halde kuluçkanın 


\section{Etlik Piliç Üretiminde Civciv Kalitesini Etkileyen Faktörler ve Kalite Sınıflandırılmasında Kullanılan Kalitatif Parametreler}

ilk dönemlerinde embriyonun iç kabuk zarına yapışmasına ve embiriyonun daha gelişim aşamasında iken ölümüne neden olabilir (Elibol, 2018).
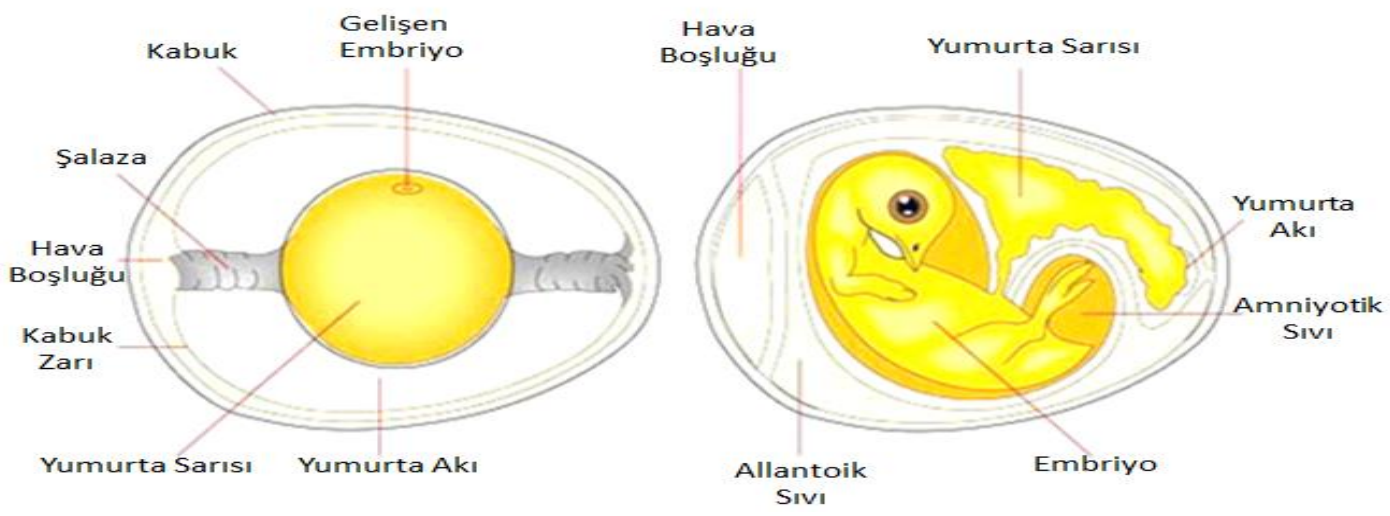

Şekil 6. Embriyo gelişimi sırasında civcivin yumurta içerisinde dönmesi

Yumurta içi besleme; Kuluçka döneminin son birkaç gününde embriyonun amnion sivisina besin maddesi (karbonhidratlar, aminoasitler, proteinler, mineraller, vitaminler vs.) verilmesidir (Şekil 7.). Kuluçka sırasında in ovo besleme yöntemi uygulanan civciv henüz yumurta içinde iken kuluçka faaliyeti sona ermeden yem tüketmeye başlamaktadır. İn ovo beslemenin yapılmasiyla, karın boşluğuna alınan yumurta sarı kesesi içeriği besin maddeleri yönünden zenginleştirilir.

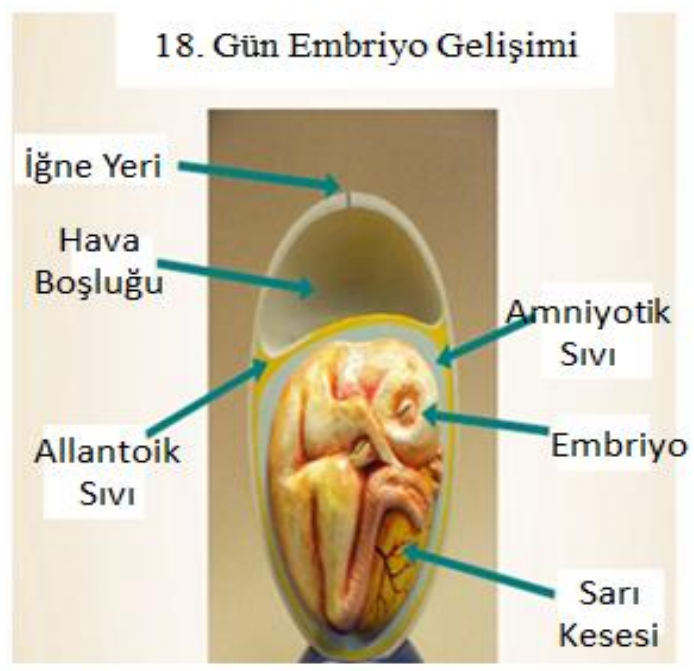

Şekil 7. Yumurta içi besleme

Böylece kuluçka sonrası ölüm oranı azaltılmaya, enzim aktiviteleri (sükrazizomaltaz ve amino-peptidaz) arttırılmaya, iştah arttırılarak kuluçka sonrası yem tüketimi uyarılmaya, bağırsak antijenlerine karşı bağışıklık sistemi güçlendirilmeye, bağırsak gelişimi hızlandırılmaya, kas gelişimi ve göğüs eti randımanı yükseltilmeye çalışılmaktadır (Uni ve Ferket, 2004). Ayrıca kuluçkanın 16-20. günleri arasinda uygulanan in ovo uygulamasının çıkış gücünü etkilemeksizin hastalığa karş1 büyük oranda koruma sağladığ1 gözlemlenmiştir (Sharma ve Burmester, 1982).

In ovo uygulamasının zamanı ve yerinin belirlenmesinde embriyonik gelişim aşamalarının bilinmesi önemlidir. Kuluçkanın geç döneminde özellikle in ovo enjeksiyon için kullanılan ve embriyoyu çevreleyen yapıları ifade eden allantoik kese, amniyotik siv1, yumurta sarısı kesesi, embriyo gövdesi (intra embriyonik alan) ve hava boşluğu olmak üzere beş bölge bulunmaktadır (Williams ve Hopkins, 2011). Salahi ve ark. (2011)'nna göre embriyonal dönemin 18.5-19. günlerinde besin maddelerinin in ovo enjeksiyonu için en ideal zamanın inkübasyonun 453. saati olduğu bildirilmiştir.

\section{Kuluçka sonrası}

Yumurtadan çıkmasını takip eden ilk günlerde civcivlerin maruz kaldığı çevre, yapılan bakım ve uygulamalar sürünün dönem sonu canlı ağırlığını etkilemektedir. Üretim döneminin ilk 10-14 günü civciv 


\section{Etlik Piliç Üretiminde Civciv Kalitesini Etkileyen Faktörler ve Kalite Sınıflandırılmasında Kullanılan Kalitatif Parametreler}

dönemi olarak adlandırılır. $\mathrm{Bu}$ dönem boyunca hayvanın ihtiyacı olan özel koşulları sağlayacak özel kümes içi şartlar temin edilmeli ve bunlara ek olarak ihtiyacı olan besin maddeleri ve su uygun miktar ve koşullar da sağlanmalıdır. Kuluçkadan çıktıktan sonraki ilk 4 gün erken dönem olarak adlandirilır. Civciv yumurtadan çıktı̆̆ında tam gelişmediği için, erken dönemde sağlanan koşullar ve uygulamalar sahadaki performansi belirlemektedir. $\mathrm{Bu}$ süreçte meydana gelecek hatalar, telafisi mümkün olmayan performans kayıplarına sebep olmaktadır (Kamanlı ve Durmus, 2014)

Termoregülatör sisteminin gelişimi; Civcivler kuluçkadan çıktıklarında vücut sıcaklıkları $40-41{ }^{\circ} \mathrm{C}$ olup bu sicaklık değerini korumak için düzenleyici bir mekanizmaya sahip değildirler. $\mathrm{Bu}$ nedenle kümeslere civciv girişi olmadan birkaç saat önce ideal kümes sicaklığ 1 olan $33-35^{\circ} \mathrm{C}$ aralığında sicaklık sağlanmalı ve her hafta bu sicaklık değerinden $3^{\circ} \mathrm{C}$ düşürülmelidir. İdeal sıcaklık değerine sahip olmayan kümeslerdeki civcivlerde vücut sicaklığ dengelenemediğinden ölümler meydana gelmektetir. İdeal sıcaklık aralığı metabolik hızın ve dolayısıyla yaşama payı için kullanılan enerjinin en az olduğu sıcaklıktır. Bir başka deyişle bu sıcaklık aralığında net enerji, gelişme ve büyüme için maksimum düzeyde kullanılmakta bu da civcivin büyüme ve sağlık kalitesini arttırmaktadır. İdeal sıcaklık aralığı içindeki civcivlerin rektal sicaklık değeri $40-40.6 \quad{ }^{\circ} \mathrm{C}$ 'dir (Anonim, 2019b).

Aş1lama; Yetiştirme kümeslerinde birim alan başına ticari koşullarda ortalama 16-17 adet civciv koyulmaktadır. Kümes içerisindeki bu yerleşim sıklığı düşünüldüğünde hayvanların kesime kadar sağlıklı yetişmelerini teşvik edecek civciv kalitesini arttırıcı uygulamaların yapılması gerekmektedir. Kuluçkadan sonra belli günlerde yeterli bağışıklığı sağlamak, civciv kalitesini arttırmak, yaşama gücünü arttırmak için etlik piliç yetiştiriciliğinde aşılama önemli bir yer tutmaktadır. Son yıllarda kuluçkanın çıkış evresine geçildiğinde yumurta kabuğunu kırmayan özel bir ekipman ile embriyo keseleri içerisine aşı uygulanabilmektedir. Böylece civciv çıkış anında bazı hastalıklara karşı bağışıklık kazanmış olup, kuluçka sonrası ilk 2 hafta içerisinde yapılacak aşı uygulamalarının oluşturacağ 1 stres, iş gücü vb. olumsuzlukları ortadan kaldırmaktadır.

Erken dönem besleme uygulamaları; Üretime alınan civcivin kesime kadar ki süreçte sağlıklı ve istenilen miktar ve kalitede verim vermesi için kuluçka çıkısı sonrası ilk hafta çok önemlidir. Çünkü civcivlerin 35-42 günlük besleme sürecinin ilk haftası sindirim sisteminin gelişimi, bağışıklık sisteminin gelişmesi ve iskelet sisteminin gelişimi gibi civcivin sonraki dönemlerini de etkileyecek bir çok hayati durum için erken dönem besleme uygulamasının işlevi oldukça önemlidir. Özellikle verilen yemin formu, sindirilebilirliği, besin madde içeriği ve embriyonik dönemde içeri çekilen sarı kesesi beslemesinden (lipid form) katı form (protein ve karbonhidrat) beslemesine geçişinin sorunsuz bir şekilde gerçekleşmesi için erken dönem besleme uygulamalarının rolü büyüktür (Durmuş, 2018).

Kuluçkadan çıkışta civcivin sindirim sisteminin henüz gelişmemiş olduğu, enzim aktivitelerinin son derece düşük olduğu, özellikle proteinleri sindiren enzim aktivitesinin 4 günlük yaştan sonra arttığ 1 ve yem tüketimi kapasitesinin 7 gün yaşta günlük $35 \mathrm{~g}$ gibi son derece sinırlı olduğu bilinmektedir. Fakat ilk 7 günlük civciv beslenmesi ilerleyen dönemlerin verim düzeylerini etkileyeceğinden dolayı bu dönemde verilen yemin civcivlerin en yüksek düzeyde yararlanacağ 1 şekilde olmalıdır. $\mathrm{Bu}$ nedenle yem tüketiminin arttırılması, bağışıklığın hızlandırılması, yüksek sindirilebilirliğe sahip hammaddeye ihtiyaç duyulması, özel besin madde temini ve performans artışi için uygun form ve kalitede erken dönem besleme uygulamalarının yapılması etlik piliç performans değerlerini arttırabilir (Durmuş, 2018).

\section{Civciv Kalitesinin Kalitatif Olarak Değerlendirilmesi}




\section{Etlik Piliç Üretiminde Civciv Kalitesini Etkileyen Faktörler ve Kalite Sınıflandırılmasında Kullanılan Kalitatif Parametreler}

Kuluçkahanede civciv kalitesi çeşitli gözlemsel yada sayısal kriterler dikkate alınarak kalitatif ve/veya kantitatif skorlar ile belirlenir. $\mathrm{Bu}$ ölçümler etlik piliç büyüme performansinin tahmininde kullanilır (Decuypere ve Bruggeman, 2007). Bu tahminler yapılırken civcivin kir, bulaşma ve deformasyondan uzak olması, parlak ve açık göze sahip olması, kuru ve temiz olması ve tamamen kapalı göbek deliğine sahip olması üzerinde durulan kalite kriterleridir (Deeming, 2000; Decuypere ve ark., 2001). Göbek deliğinden dışarı çıkmış sarı kesesi yada kuru membran olmamalı ve solunum sisteminde herhangi bir hastalık belirtisi görülmemelidir (Preez, 2007). Tüm vucut ve bacaklar normal bir şekilde oluşmuş olmalı, iç dizde, deride lezyon ve şişlik olmamalıdır. Gaga ve ayak parmakları sık1 ve düzgün olmalı, ayrica hareketli, aktif ve çevresiyle ilişkili ve çevreden gelen seslere tepkili olmalıdır (Tona ve ark., 2005). Günlük civcivlerde, bu parametrelerin biri ya da birkaçının eksikliği üretim boyunca elde edilen verimi düşürecektir. Kalitatif değerlendirme kapsamında görsel değerlendirme esas alınmakta kantitatif değerlendirmede ise Tona skoru ve Pasgar skoru, civciv ağırlığı, sarı kesesiz civciv ağırlığ $1, \quad$ civciv uzunluğu gibi değerlendirmeler esas alınmaktadır. Günlük civcivlerin kalitatif özellikleri ölçülüp tartılamayan özellikler olduğu için ve kantitatif skora dönüştürülemediği için zaman alıcı, başarı tekrarı oldukça zor ve subjektif bir yorumdur. $\mathrm{Bu}$ nedenlerle kuluçka sonras1 performans üzerine kalitatif özelliklerin etkilerini inceleyen çok kısıtlı sayıda çalışma yapılmış bu konuda endüstriye dönük bilgi birikimi sağlanamamıştır (Tona ve ark., 2003, 2005).

Kalitatif özellikleri kantitatif skora dönüştürmede kullanılan Tona skoru, Leuven Üniversitesi'nde Tona ve ark., (2003) tarafindan geliştirilmiştir (Çizelge 3.1). Tona skoru, göbek bölgesi, bacaklar, sarı kesesi ve aktivite gibi farklı kriterlerin değerlendirildiği bir puanlama yöntemidir (Tona ve ark., 2003). Tona ve ark (2005), civciv kalite

Çizelge 1. Civciv kalitesi için değerlendirmeye alınan farklı parametrelerin puanları (Tona ve ark., 2003) parametreleri arasındaki ilişkiyi araştırdıkları çalışmada civciv kalite parametrelerinin birbirleriyle ilişkili olduğunu belirtmiş̧lerdir. Örneğin; göbek deliği bölgesinin kötü koşullara sahip olması düşük kaliteli civciv olduğunun bir göstergesidir. Ayrıca civcivin görünüş ve aktivitesi, geri çekilen sarı ve arta kalan sarı membran miktarı da civcivin kalitesini etkileyen başlıca faktörlerdir. Tona skor yönteminde civcivler Çizelge 1'de verilen özellikler bakımından önem sıralarına göre toplam 100 puan üzerinden puanlandirilırlar. Puanlamada her bir parametre civcivin hayatta kalabilme gücündeki önemine ve anormalliğin şiddetine göre ayrı ayrı değerlendirilir ve ortalama Tona Skor değeri bulunur. Tona skor değerine göre puan 100'e yaklaştıkça kalite artmakta, uzaklaştıkça kalite düşmektedir (Kamanlı ve Durmuş, 2014). Pasgar Skor ise kuluçkadan yeni çıkmış civcivlerin kalite değerlendirilmesinde kullanılan Apgar Skor'dan uyarlanmış bir civciv değerlendirme yöntemidir. Apgar Skor kuluçka çıkışından 1 ve 5 dakika sonra iki kez uygulanır.

$\mathrm{Bu}$ skorlamada civcivin kalp atışlarına, rengine, solunumuna, hareketlerine ve uyarılara karşı verdiği tepkilere bakı1lır. Bu parametrelere 0-2 arasında değerler verilerek 10 üzerinden bir değerlendirme yapılır. $\mathrm{Bu}$ skor 7-10 arasinda ise civciv normal, 4-6 arasında ise civciv solunum desteği ile bu dönemi sorunsuz atlatabilir ama 0-3 arasında ise acil müdahaleye ihtiyaç duyulur. Pasgar Skor Çizelge 1'de belirtilen özelliklerin değerlendirilmesi ile oluşmaktadır. Pasgar Skor'da en yüksek puan 10 puandır, Çizelge 2 'de görülen 5 ölçütten her bir anormallik için 1 puan düşürülerek kaydedilir. Kuluçka sonrası bütün civcivlerin kalitesini belirlemek için en az 50 satılabilir civcivin değerlendirilmesi gerekmektedir. Her bir civcivin puanı toplanarak, civciv sayısına bölünmesi ile skor tespit edilir. Civcivlerin kaliteli olarak değerlendirilebilmesi için 9 puan ve üzeri bir değere sahip olması gerekmektedir (Kamanlı ve Durmuş, 2014). 


\section{Etlik Piliç Üretiminde Civciv Kalitesini Etkileyen Faktörler ve Kalite Sınıflandırılmasında Kullanılan Kalitatif Parametreler}

\begin{tabular}{|l|l|l|c|}
\hline \multicolumn{1}{|c|}{ Parametreler } & \multicolumn{1}{|c|}{ Değerlendirme } & \multicolumn{1}{|c|}{ Karakterler } & Puan \\
\hline Aktivite & Sırt Üstüyken Doğrulma Hızı & İyi/Zayıf & $6 / 0$ \\
\hline $\begin{array}{l}\text { Tüyler ve } \\
\text { Görünüş }\end{array}$ & $\begin{array}{l}\text { Kuruluk, Temizlik ve Islak ve } \\
\text { Kirlilik }\end{array}$ & Kuru ve Temiz/Islak/ Kirli ve Islak & $10 / 8 / 0$ \\
\hline $\begin{array}{l}\text { Karın Boşluğuna } \\
\text { Cekilen Yumurta } \\
\text { Sarısı }\end{array}$ & Karnın Sertliği ve Yüksekliği & $\begin{array}{l}\text { Normal/Büyük ve Sert Yumurta } \\
\text { Sarısı }\end{array}$ & $12 / 0$ \\
\hline Gözler & Parlaklık ve Açıklık & $\begin{array}{l}\text { Açık ve Parlak/Açık Ama } \\
\text { Mat/Kapalı }\end{array}$ & $16 / 8 / 0$ \\
\hline Bacaklar & Dik Duruş ve Enfekte & $\begin{array}{l}\text { Normal Ayak ve Tırnaklar/1 Bacak } \\
\text { Enfekte/2 Bacak Enfekte }\end{array}$ & $16 / 8 / 0$ \\
\hline Göbek & Kapalılık ve Renk & $\begin{array}{l}\text { Tamamen Kapalı ve Temiz/Açık } \\
\text { ve Koyu Renkli/Açık ve Bozuk } \\
\text { Renkli }\end{array}$ & $12 / 6 / 0$ \\
\hline Kalan Membran & Arta Kalan Zarın Boyutu & Yok/Küçük/Orta/Büyük & $12 / 8 / 4 / 0$ \\
\hline $\begin{array}{l}\text { Kalan Yumurta } \\
\text { Sarısı }\end{array}$ & Emilmeyen Sarı Büyüklüğü & Yok/Küçük/Orta/Büyük & $16 / 12 / 8 / 0$ \\
\hline
\end{tabular}

Çizelge 2. Pasgar skor kalite derecesi düşürme ölçütleri (Kamanlı ve Durmuş, 2014)

\begin{tabular}{|l|l|}
\hline \multicolumn{1}{|c|}{ Parametreler } & \multicolumn{1}{c|}{ Derece düşürmede kullanılan ölçütler } \\
\hline Aktivite & $\begin{array}{l}\text { Civcivler sırt üstü çevrildiklerinde normal pozisyonlarını almaları iki } \\
\text { saniyeden daha fazla zaman alır. }\end{array}$ \\
\hline Göbek & $\begin{array}{l}\text { Göbek küçük beyaz düğme şeklinde kapanmış, küçük siyak düğme şeklinde } \\
\text { kapanmıştır, geniş siyah düğme gibidir, göbekte sarı kalıntısı, açık göbek. }\end{array}$ \\
\hline Bacaklar & Kızarmış eklem, şişmiş eklem, şekil bozukluğu. \\
\hline Gaga & Kırmızı nokta, yumurta akı ile bulaşmış burun deliği, şekil bozukluğu. \\
\hline Göbek & Sarı tamamen tükenmiş veya arta kalmış sarıdan kalan sertlik. \\
\hline
\end{tabular}

Dünyada, etlik piliç eti üretiminde ekonomikliğe ve et kalitesine doğrudan etki edebilecek bir faktör olan civciv kalitesi konusunda bilgi eksikliği olup, günlük civcivlerin kalitatif özellikleri hakkındaki kaynaklar sınırlıdır. Türkiye'de ise civciv kalitesi üzerine Durmuş (2018) tarafından yapılmış tek bir özgün çalışma ile birlikte Şeremet (2012) ve Kamanlı ve Durmuş (2014) tarafından yazılmış yalnızca özet bilgi mahiyetinde iki derleme yayın mevcuttur. Durmuş (2018) yaptı̆̆ çıkışı sonrasında civciv kalitesinin değerlendirilmesinde 4 parametreyi (göz, bacak, tüy rengi ve civciv boyu) baz almıştır. Kaliteyi belirleyen puanlama ise Çizelge 3'te verilen kriterlere göre yapılmıştır. Her bir parametre için belirlenen puanların toplamı yardımıla civcivin kalite puanı belirlenmiştir. Buna göre 80-100 puana sahip civciv yüksek kaliteli, 60-79 puana sahip civciv düşük kaliteli ve 60 puandan aşağ 1 puana sahip bir civciv ise 1skarta olarak değerlendirilmiştir (Durmuş, 2018). Civciv boyuna standart getirmek için deneme öncesinde 200 adet günlük civciv üzerinde ön çalışma yapılmış ve standart uzunluklar belirlenmiştir. Civciv uzunluğu ölçülürken gaga ile orta parmak arasındaki mesafe dikkate alınmıştır. Tüy rengi ise boyun bölgesindeki tüylerin renk tonuna bakılarak değerlendirilmiştir. $\mathrm{Bu}$ kriterlerin ağırlıklı puanları (bacak \%30, göz $\% 30$, tüy rengi $\% 20$, civciv boyu \%20) ve her bir kriter için 


\section{Etlik Piliç Üretiminde Civciv Kalitesini Etkileyen Faktörler ve Kalite Sınıflandırılmasında Kullanılan Kalitatif Parametreler}

kaliteyi düşüren olumsuzluklara göre puanlar belirlenirken civciv kalitesi üzerine etkileri objektif olarak dikkate alınmaya çalışılmıştır (Durmuş, 2018).

Çizelge 3. Civciv kalite parametrelerinin puanlanması (Durmuş, 2018)

\begin{tabular}{|l|l|c|}
\hline \multicolumn{1}{|c|}{ Parametre } & \multicolumn{1}{|c|}{ Kriter } & Puan \\
\hline \multirow{4}{*}{ Bacak } & Kusursuz & 30 \\
\cline { 2 - 3 } & Eklemde şişlik ve dik duruş & 15 \\
\cline { 2 - 3 } & $\begin{array}{l}\text { Bacak ve/veya Parmaklarda şekil ve/veya } \\
\text { renk bozukluğu }\end{array}$ & 15 \\
\hline \multirow{4}{*}{ Göz } & Kusursuz & 30 \\
\cline { 2 - 3 } & Açık ama mat veya kısık göz & 15 \\
\cline { 2 - 3 } & Kapalı & 0 \\
\hline \multirow{4}{*}{ Tüy Rengi } & Koyu sarı (DSM-S 4-5) & 20 \\
\cline { 2 - 3 } & Orta Sarı (DSM-S 2-3) & 15 \\
\cline { 2 - 3 } & Açı sarı (DSM-S 1>) & 10 \\
\hline \multirow{3}{*}{ Civciv Boyu } & Uzun (19.6 cm <) & 20 \\
\cline { 2 - 3 } & Orta (19.2-19.6 cm) & 10 \\
\cline { 2 - 3 } & Kisa $(<19.2 \mathrm{~cm})$ & $\mathbf{1 0 0}$ \\
\hline Toplam Puan & $\mathbf{8 0 - 1 0 0}$ \\
\hline Yüksek Kaliteli Civciv & & $\mathbf{6 0 - 7 9}$ \\
\hline Düşük kaliteli civciv &
\end{tabular}

DSM-S; Yumurta sarısı renk ölçüm skalası

Deneme başlangıcında canlı ağırlık dikkate alınmadan yapılan kalite siniflandırmasina göre yüksek kaliteli civcivlerin düşük kaliteli civcivlere göre ortalamada $1.32 \mathrm{~g}$ daha yüksek canlı ağırlı̆̆a sahip olduğu bildirilmiştir (Durmuş, 2018). Bu sonuç daha önce yapılan bir çok çalışmanın ortak sonucu olarak canlı ağırlı̆̆ yüksek olan civcivlerin daha kaliteli olduğu tezini desteklemektedir. Ayrıca Durmuş (2018) yaptığı çalışmada, yüksek kaliteli civcivlerin deneme boyunca daha yüksek canlı ağırlığa sahip olduğunu, yemden yararlanma oranlarının daha iyi olduğunu, ölüm oranlarının daha düşük olduğunu ve piliç başına ortalamada $28.75 \mathrm{~g}$ daha yüksek kesim canlı ağırlığana sahip oldukları belirtilmiştir. Bu sonuçlar etlik piliç üretiminin ekonomik yapısını etkilediğinden ülkemiz adına oldukça önemlidir. Deneme sonu canlı ağırlık değerleri düşünüldüğünde tek bir piliç baz alındığında kayda değer bir rakam gibi gözükmese de etlik piliç üretiminin yapıldığ 1 büyük kapasiteli kümesler düşünüldüğünde bu miktarın tonlar ile ifade edileceği düşünülmektedir.

\section{Sonuc}

Etlik piliç üretiminde doğal olarak kaliteli yem ve civciv, kaliteli ve verimli bir üretimin değişmez temelidir. Fakat civciv kalitesinin objektif değerlendirilmesi ve bunun besi performansına etkisi henüz ülkemizde dikkatle irdelenen bir araştırma alanı olmamıştır. $\mathrm{Bu}$ konudaki çalışmaların çoğaltılması ile performans değerleri belli olan farklı kalitedeki civcivlerin, yetiştiriciler tarafından amaca uygun şekilde tanınması, seçme işleminin daha garantili ve daha kolay yapılmas1 mümkün olacaktır. $\mathrm{Bu}$ durum ise kalitesi düşük civcivlerle üretime başlanıldığı durumda ileride telafi edilemeyen verim kayıplarının ortadan kaldırmasına, özel bir yemleme-besleme sisteminin dizayn edilmesine ve daha ekonomik bir üretimin yapılmasına imkan sağlayacaktır. Böylece üretim aşamasında ekonomikliği olumsuz yönde etkileyecek olan civciv ölümleri, büyüme geriliği düşük kesim ağırlığı gibi istenmeyen durumlar da en az düzeye indirilecektir. Yüksek ve düşük kaliteyi ayırt etmede kullanılan bu metotların doğruluğu yapilacak olan yeni çalıșmalar ile desteklenmelidir. Sonuçların birbirine paralel çıkması halinde belirlenen kalite 


\section{Etlik Piliç Üretiminde Civciv Kalitesini Etkileyen Faktörler ve Kalite Sınıflandırılmasında Kullanılan Kalitatif Parametreler}

parametrelerinin insan gücüyle yapılması zor, kişiden kişiye değişen ve zaman alıcı bir iş olması nedeniyle, işi pratikleştirmek, kaliteyi tekrarlanabilir kılmak için civcivlerde bu siniflandirmayı yaparken baz alınan kalite özelliklerini tanıyan yüksek teknolojiye dayalı makineler üretilebilir. Böylece kuluçka sonrası civcivlerin yetiştirme kümeslerine gitmeden önce kalite siniflandırılması yapıldığından, kalite derecelerine göre sınıflandırılmış her grup civcivin performans bilgileri daha başından tespit edilmiş olacaktır. Böylece her şeyden önce farklı kalitedeki civcivlerin performanslarına göre fiyatlandırma yapılacaktır. Sonuç olarak yüksek kaliteli civcivler daha yüksek fiyatla satılacağından damızlı işletmeleri yumurtalarının ve civcivlerinin kaliteli olmas1 için gereğini yapacaklardır.

\section{Kaynaklar}

Anonim,

(2019a).

https://www.hedefkulucka.com/kul ucka-sonuclarini-etkileyen-

faktorler/, (Erişim Tarihi, 27.09.2019, Saat, 10:18).

Anonim,

(2019b).

http://www.clouds.com.tr/web/uplo ads/dosya/14970.pdf, (Erişim

Tarihi, 27.09.2019, Saat, 11:28).

Atasoy, F., Onbaşılar, E.E., Apaydın, S. (2001). Denizli ve ticari tavuk sürülerinde yumurta kalite özelliklerinin karşılaştırılması. Lalahan Hayvancılık Araştırma Enstitüsü Dergisi, 41:89-100.

Decuypere, E., Bruggeman, V. (2007). The endocrine interface of environmental and egg factors affecting chick quality. Poultry Science 86:10371042.

Decuypere, E., Tona, K., Brugeman, V., Bramelis, F. (2001). The day-old chick: a cruical hinge between breeders and broilers. World Poultry Science Journal 57:135-138.

Deeming, D.C. (2000). What is chick quality?. World Poultry Science Journal 11:34-35.

Durmuş, M. (2018) Etlik Piliçlerde Civciv Kalitesi Ve Ön-Başlatma Yemi Uygulamasinın Besi Performansina ve
Karkas Özelliklerine Etkisi, Yüksek Lisans Tezi, Çukurova Üniversitesi.

Elibol, O. (2009) Tavukçuluk Bilimi: Embriyo gelişimi ve kuluçka. M. Türkoğlu ve M. Sarıca (Ed.), 151-188, Bey Ofset Matbaac1lık, Ankara.

Hill, D. (2001). Chick length uniformity profiles as a field measurement of chick quality. Poultry Avian Biology Reviews 12:188 (Abstr).

Kamanl1, S., Durmuş İ, Demir S. (2010). Hatching Caracteristic of Abnormal Egg. Asian Journal of Animal and Veterinary Advances 5(4):271-274.

Kamanlı, S., Durmuş, İ. (2014). Civciv Kalitesi Değerlendirme Yöntemleri ve Civciv Kalitesinin İyileştirilmesi Konusundaki Son Yaklaşımlar. Tavukçuluk Araştırma Dergisi 11(1):40-44.

Kutlu, H.R. (2018). Tavukların Beslenmesi: Tavukçuluk Bilimi. M. Türkoğlu ve M.Sarıca (Ed.), 371-517, Bey Ofset Matbaacilık, Ankara.

Lapao, C., Gama, L.T., Soares, M.C. (1999). Effects of broiler breeder age and length of egg storage on albumen characteristics and hatchability. Poultry Science 78(5):640-645.

Meijerhof, R. (2009). Incubation principles: what does the embryo expect from us? Proceedings of the 20th Annual Australian Poultry Science Symposium, February 9-11 2009, University of Sydney, Sydney, s.106-111.

Mirosh, L.W., Becker, W.A. (1974). Storage and incubation temperature effects on hatching time of coturnix quail eggs. Poultry Science 53:432-434.

Moran Jr, E.T. (1990). Effects of weight, glucose administration at hatch, and delayed access to feed and water on the poult at 2 weeks of age. Poultry Science 69:1718-1723.

Okur, N. (2008). Farklı kuluçka uygulamalarının çıkış gücü ve broiler performans1 üzerindeki etkileri, Doktora Tezi, Ankara Üniversitesi.

Preez, J.H. (2007) The effect of different incubation temperatures on chick 


\section{Etlik Piliç Üretiminde Civciv Kalitesini Etkileyen Faktörler ve Kalite Sınıflandırılmasında Kullanılan Kalitatif Parametreler}

quality. (Master thesis), University of Stellenbosch.

Salahi, A., Mozhdeh, M.K., Seyed, N.M. (2011). Optimum time of in ovo injection in eggs of young broiler breeder flock. 18th European symposium on Poultry Nutrition, October 31-Noverber 042011 İzmir, s.557-559p.

Şeremet, Ç. (2012). Civciv Kalitesini Etkileyen Etmenler ve Değerlendirme Yöntemleri. Hayvansal üretim 53(1):38-43.

Sharma, J.M., Burmester, B.R. (1982). Resistance of Marek's disease at hatching in chickens vaccinated as embryos with the turkey herpesvirus. Avian Disease 26(1):134-149.

Tona, K., Bamelis, F., De Ketelaere, B., Bruggeman, V., Moraes, V. M.B., Buyse, J., Onagbesan, O., Decuypere, E. (2003). Effects of egg storage time on spread of hatch, chick quality, and chick juvenile growth. Poultry Science 82:736-741.

Tona, K., Onagbesan, O., Jego, Y., Kamers, B., Decuypere, E., Bruggeman, V. (2004). Comparison of embryo physiological parameters during incubation, chick quality and growth performance of three lines of broiler breeders differing in genetic composition and growth rate. Poultry Science 83:507-513.

Tona, K., Bruggeman, V., Onagbesan, O., Bamelis, F., Gbeassor, M., Mertens, K., Decuypere, E. (2005). Day-old chick quality: relationship to hatching egg quality, adequate incubation practice and prediction of broiler performance. Poultry Avian Biology Reviews 16:109-119.

Tona, K., Onagbesan, O., De Ketelaere, B., Bruggeman, V., Decupere, E., (2007). A model for predicting hatchability as a function of flock age, hatchability, storage time and season. European Poultry Science 71: 30-34.

Uni, Z., Ferket, P.R. (2004). Methods for early nutrition and their potential.
World's Poultry Science Journal 60:101-111.

Williams, C. J., Hopkins, B.A. (2011). Field evaluation of the accuracy of vaccine deposition by two different commercially available in ovo injection systems. Poultry Science 90(1):223-226. 